\title{
ON A FIXED POINT THEOREM OF CONTRACTIVE TYPE ${ }^{1}$
}

\author{
CHI SONG WONG
}

AbStract. A refinement of the proof of a recent fixed point theorem of Caristi is obtained.

The main purpose of this paper is to refine the proof of the following recent result of James Caristi [3].

THEOREM. Let $f$ be a self-map on a nonempty complete metric space $(X, d)$. Suppose that there exists a lower semicontinuous function $V$ of $X$ into $[0, \infty)$ such that

$$
d(x, f(x)) \leqslant V(x)-V(f(x)), \quad x \in X .
$$

Then $f$ has a fixed point.

Proof. Let $x_{0} \in X$ and $\nu$ be a nonzero ordinal. Suppose that there exists a net $\left\{x_{\beta}\right\}_{\beta<\nu}$ in $X$ such that:

(i) if $\beta$ is an isolated nonzero ordinal less than $\nu$, then $x_{\beta}=f\left(x_{\beta-1}\right)$;

(ii) if $\beta$ is a limiting ordinal less than $\nu$, then the net $\left\{x_{\alpha}\right\}_{\alpha<\beta}$ converges to $x_{\beta}$;

(iii) for all $0 \leqslant \alpha<\beta<\nu, d\left(x_{\alpha}, x_{\beta}\right) \leqslant V\left(x_{\alpha}\right)-V\left(x_{\beta}\right)$. If $\nu$ is an isolated ordinal, define $x_{\nu}=f\left(x_{\nu-1}\right)$ and note that for $\alpha<\nu$,

$$
\begin{aligned}
d\left(x_{\alpha}, x_{\nu}\right) & \leqslant d\left(x_{\alpha}, x_{\nu-1}\right)+d\left(x_{\nu-1}, x_{\nu}\right) \\
& \leqslant\left(V\left(x_{\alpha}\right)-V\left(x_{\nu-1}\right)\right)+\left(V\left(x_{\nu-1}\right)-V\left(x_{\nu}\right)\right)=V\left(x_{\alpha}\right)-V\left(x_{\nu}\right) .
\end{aligned}
$$

Suppose now that $\nu$ is a limiting ordinal. We claim that $\left\{x_{\beta}\right\}_{\beta<\nu}$ is a Cauchy net. Suppose not. Then there exists $\varepsilon>0$ and a strictly increasing sequence $\left\{\alpha_{n}\right\}$ in $(0, \nu)$ such that $d\left(x_{\alpha_{2 n}}, x_{\alpha_{2 n-1}}\right) \geqslant \varepsilon$ for all $n$. Thus

$$
\begin{aligned}
\infty & =\sum_{n=1}^{\infty} d\left(x_{\alpha_{2 n}}, x_{\alpha_{2 n-1}}\right) \\
& \leqslant \sum_{n=1}^{\infty}\left(V\left(x_{\alpha_{2 n}}\right)-V\left(x_{\alpha_{2 n-1}}\right)\right) \leqslant V\left(x_{0}\right),
\end{aligned}
$$

a contradiction. So $\left\{x_{\beta}\right\}_{\beta<\nu}$ is Cauchy and therefore, by completeness of

Received by the editors July $23,1975$.

AMS (MOS) subject classifications (1970). Primary 47H10; Secondary 54H25.

Key words and phrases. Completeness, lower semicontinuity, transfinite induction.

1 This research was partially supported by National Research Council of Canada, Grant A8518 and a grant from Canadian Mathematical Congress. It was prepared while the author was at the Summer Research Institute at Dalhousie University. 
$(X, d),\left\{x_{\alpha}\right\}_{\alpha<\nu}$ converges to some point which we shall define to be $x_{\nu}$. Let $\alpha<\nu$. Since $V$ is lower semicontinuous,

$$
\begin{aligned}
d\left(x_{\alpha}, x_{\nu}\right) & =\lim _{\beta<\nu} d\left(x_{\alpha}, x_{\beta}\right) \leqslant \liminf _{\beta<n}\left(V\left(x_{\alpha}\right)-V\left(x_{\beta}\right)\right) \\
& =V\left(x_{\alpha}\right)-\limsup _{\beta<\nu} V\left(x_{\beta}\right) \leqslant V\left(x_{\alpha}\right)-V\left(x_{\nu}\right) .
\end{aligned}
$$

This shows that for any ordinal $\nu$, there exists a net $\left\{x_{\beta}\right\}_{\beta<\nu}$ in $X$ with properties (i), (ii), and (iii). If $f$ has no fixed point, then $\left\{V\left(x_{\alpha}\right)\right\}_{\alpha<\nu}$ is strictly decreasing and so a contradiction is obtained if we take the cardinality of $\nu$ larger than that of $X$ (or $\{1,2, \ldots\}$ ). Q.E.D.

The next result follows from the above theorem.

Proposition. Let $(X, d)$ be a nonempty complete metric space. Let $f$ be a selfmap on $X$. Suppose that there exists a lower semicontinuous function of $X$ into $[0, \infty)$ such that for any $x$ in $X$ with $x \neq f(x)$, there exists $y$ in $X \backslash\{x\}$ such that $d(x, y) \leqslant V(x)-V(y)$. Then $f$ has a fixed point.

We are informed by the referee and W. A. Kirk that a theorem which is equivalent to Caristi's theorem was announced by I. Ekeland in 1972 [5], a proof [8] of Ekeland's theorem using Zorn's lemma can be found in a recent paper of A. Brønsted [2], and a proof of Caristi's theorem without using Zorn's lemma was obtained by F. E. Browder [1]. Applications of the above theorem of Caristi can be found in [3], [4], [6], [7], [8].

\section{REFERENCES}

1. F. E. Browder, On a theorem of Caristi and Kirk, Proc. Seminar on Fixed Point Theory and its Applications, Dalhousie University, June 1975 (to appear).

2. A. Brønsted, On a lemma of Bishop and Phelps, Pacific J. Math. 55 (1974), 335-341.

3. J. Caristi, Fixed point theorems for mappings satisfying inwardness conditions, Trans. Amer. Math. Soc. 215 (1976), 241-251.

4. J. Caristi and W. A. Kirk, Geometric fixed point theory and inwardness conditions, Proc. Conf. on Geometry of Metric and Linear Spaces, Michigan State University, 1974 (to appear).

5. I. Ekeland, Sur les problémes variationnels, C. R. Acad. Sci. Paris Sér. A-B 275 (1972), A1057-A1059. MR 46 \#9768.

6. W. A. Kirk, Caristi's fixed point theorem and the theory of normal solvability, Proc. Seminar on Fixed Point Theory and its Applications, Dalhousie University, 1975 (to appear).

7. W. A. Kirk and J. Caristi, Mapping theorems in metric and Banach spaces, Bull. Acad. Polon. Sci. 23 (1975).

8. W. A. Kirk, Caristi's fixed point theorem and metric convexity (to appear).

Department of Mathematics, University of Windsor, Windsor, Ontario, Canada N9B 3 P4 